\title{
Invasive species in the grasslands of the Central Caucasus
}

\author{
Victoria Chadaeva*, Nelli Tsepkova, Rustam Pshegusov, Elena Stepanyan, Albert Zhashuev, Alina Maremkulova, \\ and Zalim Khanov
}

Tembotov Institute of Ecology of Mountain Territories of Russian Academy of Science, 360051 Nalchik, Russia

\begin{abstract}
Biological invasions and grassland transformation are significant problems in pasture ecosystems of the Central Caucasus. The aim was to study the main patterns of invasive processes in grasslands and included identification the main vegetation parameters and abiotic factors affecting the invasion and distribution of alien species (Erigeron annuus, Ambrosia artemisiifolia, and Xanthium albinum) in plant communities. We assessed vegetation parameters of steppe grasslands with the presence of alien species within 122 model plots on plains, in foothills and low mountains (250-1000 m above sea level). We also modeled the current habitats of the species in grasslands of the Central Caucasus by using the Maxent method. The most suitable for invasion and distribution of Erigeron annuus are productive grasslands (NDVI is 0.25 and more) of the foothills and low mountains with a moderately warm humid climate (average annual temperature is $5-10^{\circ} \mathrm{C}$; precipitation of the most humid quarter is $240-300 \mathrm{~mm}$ ). The most suitable for Ambrosia artemisiifolia are medium-productive grasslands (NDVI is 0.25-0.38) of the foothills and low mountains with low vegetation coverage $(65-85 \%)$ and moderately humid climate (precipitation of the most humid quarter is $225-275 \mathrm{~mm}$ ). The most suitable for Xanthium albinum at present are dry unproductive disturbed grasslands of plains.
\end{abstract}

\section{Introduction}

Biological invasions are one of the main significant environmental problems leading to degradation of grasslands globally [1-4]. Whereas earlier the grasslands were relatively resistant to invasion of alien species, nowadays climate warming, overgrazing and development of the road network significantly increased the risk of biological invasions in these environments. The problem is also relevant for the Central Caucasus, where there is an intense penetration of alien plant species into the lowland and mountain grasslands. Given the functioning in the region of the agricultural sector, biological invasions here can have severe socioeconomic consequences.

The alien plant species that are widespread in the lowland and foothill regions of the Central Caucasus and currently penetrate into the grasslands include Erigeron annuus (L.) Pers., Ambrosia artemisiifolia L., and Xanthium albinum (Widd.) Scholz \& Sukopp. Distribution of these species, as well as overgrazing, is a key factor in grassland degradation, which changes the forage value and the biodiversity of pastures.

The native range of Erigeron annuus includes the eastern United States, where the species grows along weedy places, roadsides, and river banks, in meadows and steppes [5]. The first reliable information on the growth of Erigeron annuus in the Caucasus dates back to 1930s (weedy places of the coast of Abkhazia and Georgia [6]). The native range of Ambrosia artemisiifolia covers the eastern and southeastern United States and southern Canada. The species grows along roadsides, weedy places, and river banks, on agricultural land [7]. For the first time in the Caucasus, Ambrosia artemisiifolia was noted back in 1914 in the Krasnodar krai [8], from where it spread widely throughout the region. Xanthium albinum species is also of North American origin. It widely distributed on wetlands, agricultural land, and roadsides. The appearance time of Xanthium albinum in the Caucasus is not known for certain.

Data on the patterns of expansion of the alien species into the grasslands are limited. According to our observations, the invasion of Erigeron annuиs, Ambrosia artemisiifolia, and Xanthium albinum into the grasslands is associated with the transfer of seeds by transport traffic and disturbance of pasture due to overgrazing. The purpose of this study was to identify the main patterns of invasive processes in grasslands of the Central Caucasus. The objectives were a) to study the main parameters of vegetation affecting the distribution of alien species in plant communities; b) to identify the main abiotic factors that limit (or stimulate) the distribution of alien species in the study area.

\section{Materials and methods}

\subsection{Study area}

We pursued the studies in the Central Caucasus (between $42^{\circ} 54^{\prime}-44^{\circ} 01^{\prime} \mathrm{N}$ and $43^{\circ} 52^{\prime}-43^{\circ} 03^{\prime} \mathrm{E}$ ) within the elbrusskiy and terskiy variants of vertical zonation of the northern macroslope in the Central Caucasus in 2017 -

\footnotetext{
* Corresponding author: v chadayeva@mail.ru
} 
2021. The lack of broad-leaved forest belt and pronounced xerophytization of landscapes determine the peculiarities of the elbrusskiy variant of vertical zonation [9]. Its belt spectrum consists of meadow steppes (foreststeppes), steppe meadows, subalpine, alpine, subnival and nival belts. Mesophytization of landscapes is peculiar to the terskiy variant of vertical zonation. The broad-leaved forest belt, subalpine, alpine, subnival and nival belts are represented in its composition.

The mountainous relief, altitude above sea level, and the arrival of western air masses from the Atlantic form a relatively cold and humid continental climate of the study area in mountain regions. The climate of the lowland regions is continental, relatively hot and dry.

\subsection{Data collection and measurements}

We established 112 model plots in steppe grasslands with the presence of alien species within the plains, foothills, and low mountain regions of the Central Caucasus from $250 \mathrm{~m}$ to $1000 \mathrm{~m}$ above sea level (42 model plots for Erigeron annuus, 40 model plots for Ambrosia artemisiifolia, and 30 model plots for Xanthium albinum). The model plots were located at the gentle slopes $\left(5-20^{\circ}\right)$, on river terraces, and on plain areas near or far from villages. The area of each plot was $900 \mathrm{~m}^{2}$. No alien plants were found in steppe midmountain pastures or subalpine and alpine high mountain grasslands of the study area.

We visually assessed vegetation coverage and coverage of each species on model plots and expressed as a percentage (Table 1).

Table 1. Vegetation parameters of model plots within grasslands with the presence of alien species

\begin{tabular}{|c|c|c|}
\hline Vegetation parameter & \begin{tabular}{|c|} 
Mean \pm standard \\
deviation
\end{tabular} & Min-Max \\
\hline \multicolumn{3}{|c|}{ Erigeron annuus $(\mathrm{n}=42)$} \\
\hline Vegetation coverage, $\%$ & $92 \pm 9.5$ & $65-100$ \\
\hline Grass height, $\mathrm{cm}$ & $31 \pm 13.5$ & $5-55$ \\
\hline Species richness & $28 \pm 8.7$ & $10-43$ \\
\hline Shannon index & $2.27 \pm 0.37$ & $1.16-2.7$ \\
\hline Berger-Parker index & $0.27 \pm 0.15$ & $0.13-0.8$ \\
\hline Coverage of the alien species, $\%$ & $14.8 \pm 12.3$ & $2-60$ \\
\hline \multicolumn{3}{|c|}{ Ambrosia artemisiifolia $(\mathrm{n}=40)$} \\
\hline Vegetation coverage, $\%$ & $82 \pm 12.1$ & $60-100$ \\
\hline Grass height, $\mathrm{cm}$ & $17.7 \pm 13.4$ & $2-50$ \\
\hline Species richness & $24 \pm 7.6$ & $11-39$ \\
\hline Shannon index & $2.05 \pm 0.49$ & $0.7-2.7$ \\
\hline Berger-Parker index & $0.33 \pm 0.18$ & $0.18-0.9$ \\
\hline Coverage of the alien species, $\%$ & $10.9 \pm 6.1$ & $2-20$ \\
\hline \multicolumn{3}{|c|}{ Xanthium albinum $(\mathrm{n}=30)$} \\
\hline Vegetation coverage, $\%$ & $77 \pm 13.5$ & $60-90$ \\
\hline Grass height, $\mathrm{cm}$ & $12.4 \pm 9.2$ & $2-25$ \\
\hline Species richness & $22 \pm 6.8$ & $10-34$ \\
\hline Shannon index & $2.02 \pm 0.48$ & $0.6-2.4$ \\
\hline Berger-Parker index & $0.36 \pm 0.19$ & $0.2-0.9$ \\
\hline Coverage of the alien species, $\%$ & $15.7 \pm 8.4$ & $5-25$ \\
\hline
\end{tabular}

Grass height $(\mathrm{cm})$ was recorded by the average height of cereal leaves. Species richness represented the total number of species within each plot. We applied
Shannon and Berger-Parker indices to calculate the alpha diversity (evenness) and degree of dominance of plant communities. Plant species nomenclature follows TPL [10]. We used multiple regression analysis in the Statistica 10 to identify the main vegetation and environmental parameters of the model plots that affect the coverage of alien species in grasslands. Shannon and Berger-Parker indices were calculated using Past 4.0.

To identify abiotic factors limiting the distribution of Erigeron annuus, Ambrosia artemisiifolia, and Xanthium albinum in grasslands, we modeled the current habitats of the species in the Central Caucasus by using the Maxent method (Maxent software, v 3.4.1; linear/quadratic features type; 0.5 regularization multiplier). The Maxent method allows one to select the habitats similar to those in which the species was found by distributions of the properties of environment [11, 12]. The habitats identified with the highest probability of detecting the species are the most suitable. The analysis includes GPS coordinates of 112 habitats of the species in grasslands (42 presence points for Erigeron annuus, 40 presence points for Ambrosia artemisiifolia, and 30 presence points for Xanthium albinum (Application)), identified during field research in 2017 2021. To obtain an adequate model, a calculation was carried out in five replicates for uniform distribution of test and training samples.

WorldClim climate models, which include 19 bioclimatic variables [13], were used as a basis for interpolation of data on spatial distribution of the species. We also used measurements of reflected solar radiation from the Landsat $8 \mathrm{OLI} / \mathrm{TRS}$ satellite and normalized difference vegetation indices (NDVI) calculated on the basis of the mosaic of the study area. Based on SRTM (Shuttle radar topographic mission), we calculated altitude and morphometric characteristics of relief: slope, exposure, various types of curvature, etc. $[14,15]$. Environmental layers were clipped to the study area at $30 \mathrm{~m}^{2}$ resolution.

The graphic representation of the research results was formulated in the maps of the species distribution in the PanoplyWin (v 5.9). Visualization of the probability of suitability of species habitats is carried out according to the ranked values of the standard Maxent palette in gradation of colors from blue (occurrence " 0 ") to red (occurrence "1"). For potentially suitable grasslands for the species, probability values are acceptable from 0.5 to 0.8 , for optimal habitats - above 0.8 .

\section{Results}

\subsection{Vegetation and environmental parameters affecting the coverage of alien species in grasslands}

We used grass height, vegetation coverage, species richness, Shannon and Berger-Parker indices, altitude above sea level $(\mathrm{m})$, and steepness $\left(^{\circ}\right)$ in multiple regression analysis to identify the main vegetation and environmental parameters of model plots affecting the 
coverage of each studied species. We created three models. They were Ambrosia artemisiifolia model (Amodel), Erigeron annuus model (E-model), Xanthium albinum model (X-model).

A-model explained approximately $74 \%$ of variation in independent variables at $\mathrm{P}<0.001$ significance level (Table 2).

Table 2. Multiple regression analysis data showing significance levels of vegetation and environmental variables in determination of Ambrosia artemisiifolia coverage in grasslands

\begin{tabular}{|c|c|c|c|c|}
\hline $\begin{array}{c}\text { Independent } \\
\text { variable }\end{array}$ & \begin{tabular}{|c|}
$\begin{array}{c}\text { Variable } \\
\text { code }\end{array}$ \\
\end{tabular} & b & $\begin{array}{l}\text { Standard } \\
\text { error of b }\end{array}$ & t-test \\
\hline Intercept & & 26.27 & 18.12 & ns \\
\hline Vegetation coverage, $\%$ & A & -0.29 & 0.08 & * \\
\hline Altitude, $\mathrm{m}$ & B & 0.01 & 0.00 & * \\
\hline Grass height, $\mathrm{cm}$ & $\mathrm{C}$ & 0.02 & 0.09 & ns \\
\hline Steepness, ${ }^{\circ}$ & $\mathrm{D}$ & 0.07 & 0.14 & ns \\
\hline Species richness & $E$ & 0.14 & 0.25 & ns \\
\hline Shannon index & $\mathrm{F}$ & -0.45 & 7.59 & ns \\
\hline Berger-Parker index & G & 1.15 & 15.7 & ns \\
\hline \multirow{2}{*}{ Mathematical model } & $\mathrm{R}^{2}$ & Adj. $\mathrm{R}^{2}$ & P-value & SEE \\
\hline & 0.739 & 0.625 & $<0.001$ & 3.73 \\
\hline
\end{tabular}

* Significant at the 0.05 probability level; ns: nonsignificant at the 0.05 probability level; $n=42$.

Vegetation coverage was the most important variable according to it regression coefficient (b). It is followed by altitude above sea level with non-zero regression coefficient. Grass height, steepness, species richness, and Shannon and Berger-Parker indices were nonsignificant parameters $(\mathrm{P}>0.05)$ in Ambrosia artemisiifolia coverage determination. Decrease in vegetation coverage with negative regression coefficient indicated an increase in the species distribution in grasslands of the Central Caucasus. Altitude above sea level displayed a positive relationship with the species coverage. Obviously, Ambrosia artemisiifolia has a greater distribution in foothills and low mountain regions (450-1000 $\mathrm{m}$ above sea level) than in plains (250-400 m) of the study area.

E-model explained $70 \%$ of variation in independent variables at $\mathrm{P}<0.05$ significance level (Table 3 ).

Table 3. Multiple regression analysis data showing significance levels of vegetation and environmental variables in determination of Erigeron annuus coverage in grasslands

\begin{tabular}{|c|c|c|c|c|}
\hline $\begin{array}{c}\text { Independent } \\
\text { variable }\end{array}$ & \begin{tabular}{|c|}
$\begin{array}{c}\text { Variable } \\
\text { code }\end{array}$ \\
\end{tabular} & b & $\begin{array}{l}\text { Standard } \\
\text { error of } b\end{array}$ & t-test \\
\hline Intercept & & 19.11 & 41.7 & ns \\
\hline Altitude, $\mathrm{m}$ & $\mathrm{A}$ & 0.03 & 0.01 & $*$ \\
\hline Vegetation coverage, $\%$ & $\mathrm{~B}$ & 0.14 & 0.32 & $\mathrm{~ns}$ \\
\hline Grass height, $\mathrm{cm}$ & $\mathrm{C}$ & 0.22 & 0.19 & ns \\
\hline Steepness, ${ }^{\circ}$ & $\mathrm{D}$ & 0.17 & 0.41 & ns \\
\hline Species richness & $\mathrm{E}$ & 0.81 & 0.50 & ns \\
\hline Shannon index & $\mathrm{F}$ & -27.65 & 7.74 & $*$ \\
\hline Berger-Parker index & G & 11.13 & 4.73 & * \\
\hline \multirow{2}{*}{ Mathematical model } & $\mathrm{R}^{2}$ & Adj. $R^{2}$ & P-value & SEE \\
\hline & 0.704 & 0.606 & $<0.053$ & 7.8 \\
\hline
\end{tabular}

* Significant at the 0.05 probability level; ns: nonsignificant at the 0.05 probability level; $n=40$.

Altitude, Shannon and Berger-Parker indices were the only important variable affecting the coverage of Erigeron annuus in grasslands. Increase in altitude from plains to low mountain regions $(250-950 \mathrm{~m}$ above sea level) indicated an increase in the species distribution in grasslands. The species expansion within the model plots accompanied by a decrease in alpha diversity (Shannon index) and an increase in degree of dominance (BergerParker index) of plant communities. The other vegetation and environmental parameters do not have any limiting or stimulating effect on the Erigeron annuus distribution in grasslands of the Central Caucasus $(\mathrm{P}>0.05)$.

$\mathrm{X}$-model explained approximately $82 \%$ of variation in independent variables at $\mathrm{P}<0.0001$ significance level; the standard error of estimate (SSE) was quite low (Table 4).

Table 4. Multiple regression analysis data showing significance levels of vegetation and environmental variables in determination of Xanthium albinum coverage in grasslands

\begin{tabular}{|c|c|c|c|c|}
\hline $\begin{array}{c}\text { Independent } \\
\text { variable }\end{array}$ & \begin{tabular}{|c|}
$\begin{array}{c}\text { Variable } \\
\text { code }\end{array}$ \\
\end{tabular} & b & $\begin{array}{l}\text { Standard } \\
\text { error of } b\end{array}$ & t-tes \\
\hline Intercept & & 2.84 & 0.19 & $*$ \\
\hline Vegetation coverage, $\%$ & A & -0.17 & 0.02 & $*$ \\
\hline Altitude, $\mathrm{m}$ & $\mathrm{B}$ & -0.01 & 0.00 & $*$ \\
\hline Grass height, $\mathrm{cm}$ & $\mathrm{C}$ & -0.03 & 0.00 & $*$ \\
\hline Steepness, ${ }^{\circ}$ & $\mathrm{D}$ & -0.005 & 0.00 & ns \\
\hline Species richness & $\mathrm{E}$ & -0.09 & 0.01 & $*$ \\
\hline Shannon index & $\mathrm{F}$ & -0.01 & 0.00 & $*$ \\
\hline Berger-Parker index & $\mathrm{G}$ & 0.04 & 0.00 & $*$ \\
\hline \multirow{2}{*}{ Mathematical model } & $\mathrm{R}^{2}$ & Adj. $R^{2}$ & P-value & SEE \\
\hline & 0.82 & 0.79 & $<0.0001$ & 0.62 \\
\hline
\end{tabular}

$0.03 \times \mathrm{C}-0.01 \times \mathrm{B}-0.01 \times \mathrm{F}$

* Significant at the 0.05 probability level; ns: nonsignificant at the 0.05 probability level; $\mathrm{n}=30$.

These characteristics implied that the model was significant. Vegetation coverage was the most important variable. It is followed by species richness, BergerParker index, grass height, altitude, and Shannon index with non-zero regression coefficients. Steepness was the only nonsignificant parameter $(\mathrm{P}>0.05)$ in determination of Xanthium albinum coverage. Decreases in vegetation coverage, grass height, species richness, and Shannon index with negative regression coefficients indicated an increase in the species distribution in grasslands. At the same time, a decrease in these parameters characterizes an increase in level of grassland degradation. Berger-Parker index, which increased with increasing coverage of grazing-resistant secondary pasture dominants (Cynodon dactylon (L.) Pers., Elytrigia repens (L.) Nevski, Artemisia annua L., etc.), displayed a positive relationship with coverage of Xanthium albinum. The species has a greater distribution in the plains and foothills (250-400 m above sea level) than in low mountain regions $(450-800 \mathrm{~m})$ of the Central Caucasus. 


\subsection{Spatial distribution of the alien species in grasslands}

Modeling of the modern habitat of Erigeron annuus in the grasslands of the Central Caucasus, using the MaxEnt method, confirmed the wide distribution of the species in this type of ecosistems from foothills to low mountain regions (Figure 1). Here was the largest number of possible locations of the species in grasslands, including with a probability above $80 \%$. In midmountain and hight mountain regions, it is highly probable that suitable habitats for the species can be found at the road sides along the river valleys; less often, grasslands suitable for invasion of Erigeron annuus can be found at the slopes of mountains. The predicted number of grasslands potentially suitable and optimal for the species was also low on the plain regions.

The range of Ambrosia artemisiifolia in the grasslands of study area mainly encompassed the foothill regions (Figure 1). With a high probability $(80-100 \%)$, the penetration of the species into the low mountain grasslands also is possible. On the plains of study region, grasslands suitable for Ambrosia artemisiifolia were represented mainly by relatively small area adjacent to the foothills. Penetration of the species into high-altitude grasslands is currently unlikely.

The main distribution area of Xanthium albinum in the grasslands of the Central Caucasus covered a relatively large plain area, as well as the foothills and low mountains (Figure 1). In the midmountain regions, it is highly probable that species can be found in the grasslands along the settlements. The predicted number of potentially suitable grasslands is lowest in the high mountain regions.

There were three main factors affecting the invasion of Erigeron annuus in the grasslands of study area, of which the climatic factor BIO16 (precipitation of the most humid quarter) made the largest contribution to the construction of the model; NDVI (normalized differential (relative) vegetation index in summer) and BIO1 (average annual temperature) had a lesser effect (Table 5). For these parameters, the maximum values of the percentage contribution are noted. Analysis of the dependence of Erigeron annuиs on the most significant climatic factors showed that grassland suitability for the species invasion decreased with precipitation of the most humid quarter of less than $240 \mathrm{~mm}$ and more than 300 $\mathrm{mm}$, and an acceptable range of average annual temperature was from $5^{\circ} \mathrm{C}$ to $10^{\circ} \mathrm{C}$ (Figure 2). The values of NDVI suitable for growth of Erigeron annuus were quite high (at least 0.25). Thus, the spread of Erigeron annuus at present occurs mainly in productive grasslands of the foothill and low mountain regions with a moderately warm humid climate.

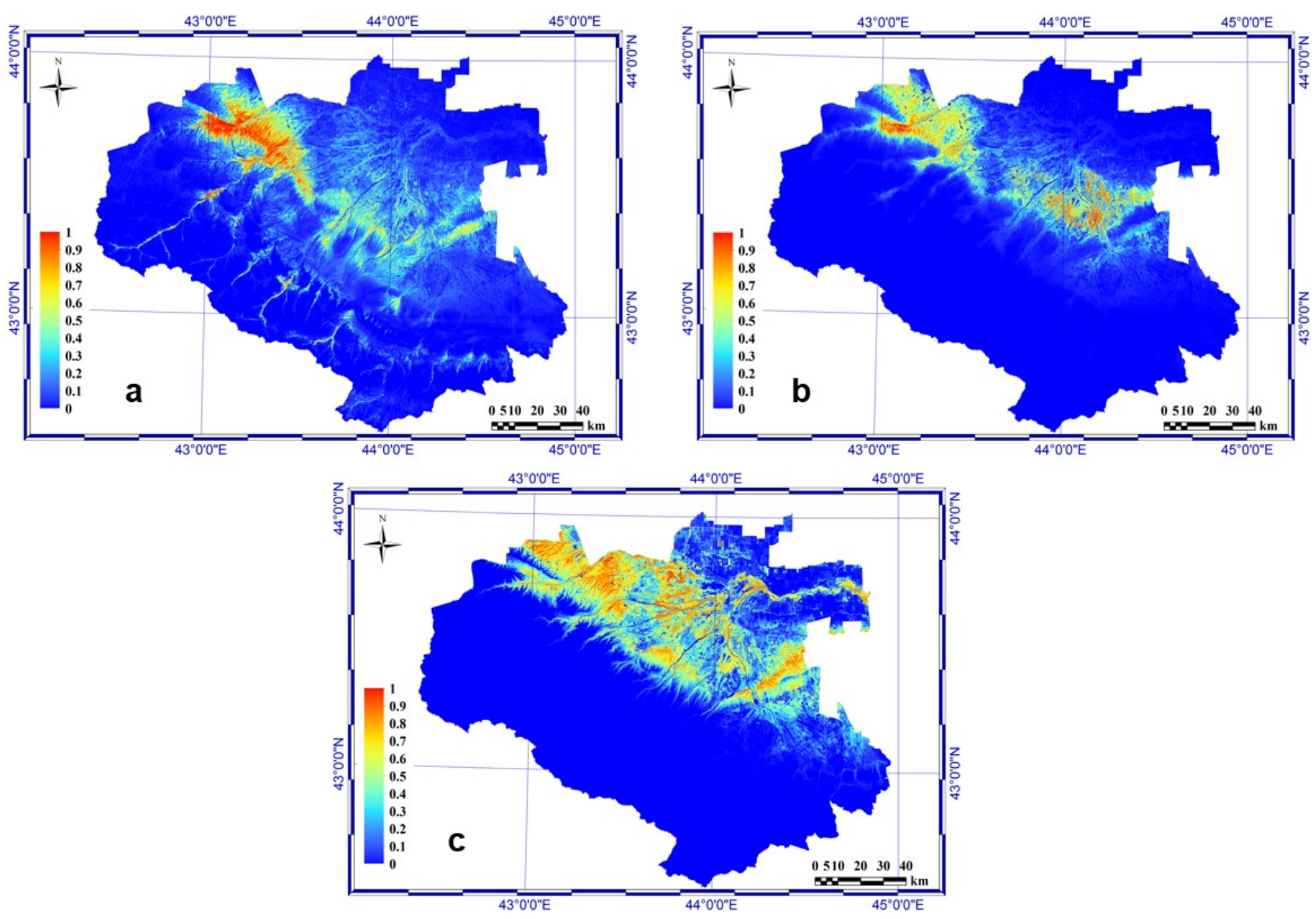

Fig. 1. Distribution map of grasslands suitable for Erigeron annuus (a), Ambrosia artemisiifolia (b), and Xanthium albinum (c) in the Central Caucasus: 0-0.4, the probability of finding the species for unsuitable habitats; $0.5-0.8$ and above 0.8 , the probability for suitable and optimal habitats, respectively. 

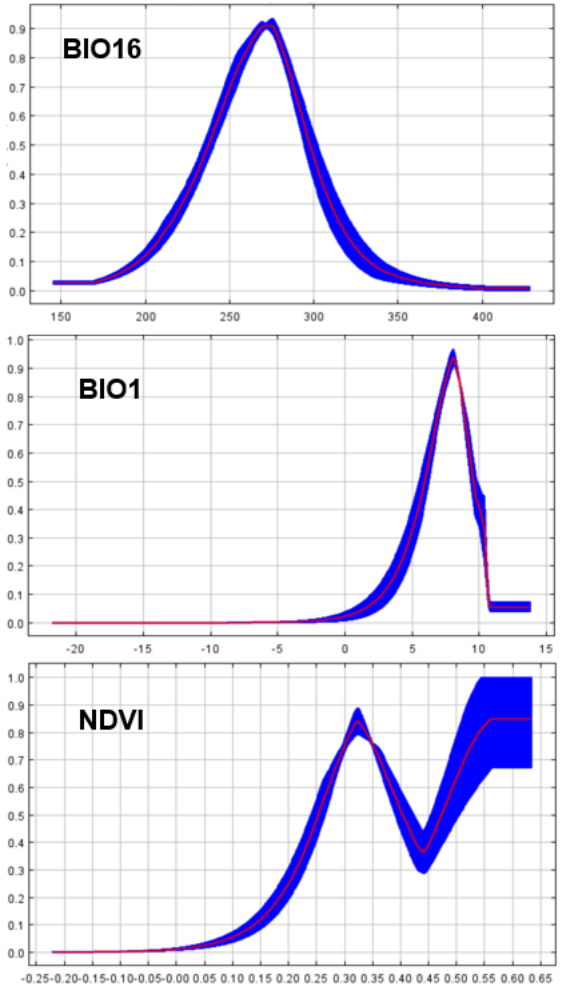

Erigeron annuus
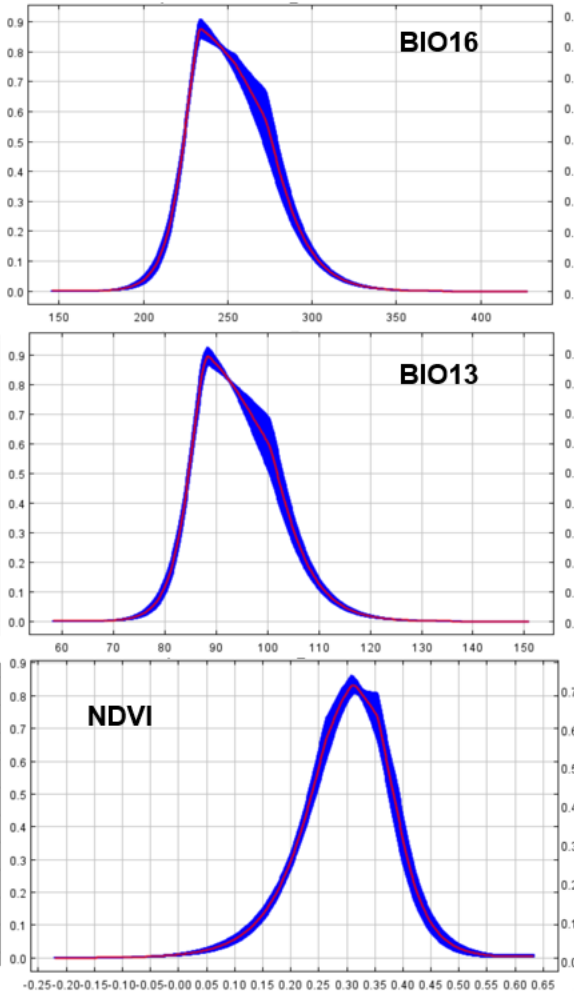

Ambrosia artemisiifolia
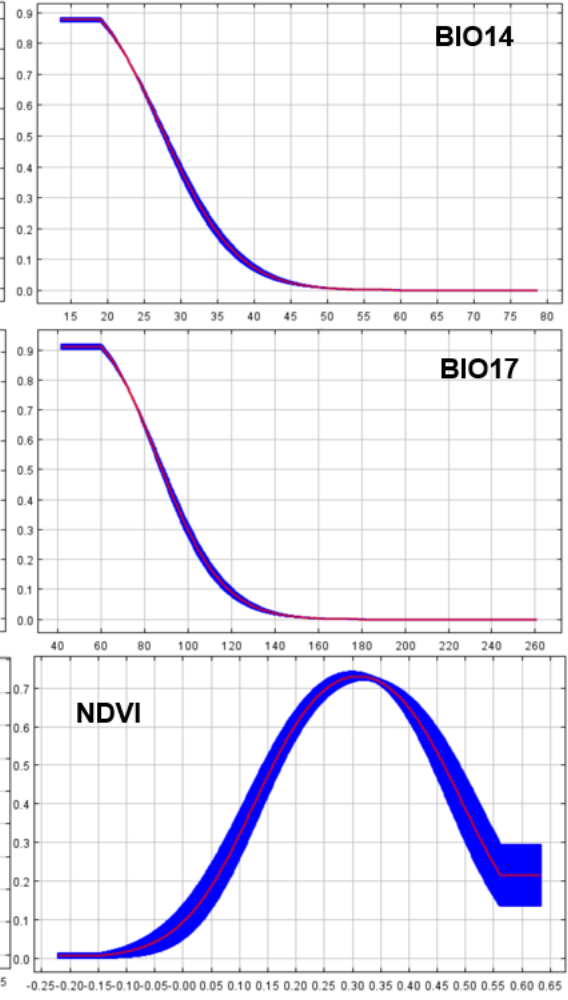

Xanthium albinum

Fig. 2. Plot of responses of presence points of alien species to the most important environmental factors. The $y$ axis is the predicted probability of suitable conditions for the species to grow in the logistic output format; the $\mathrm{x}$ axis is the value of the variable (BIO1, BIO13, BIO14, BIO16, BIO17, NDVI). The mean values of factors for replicates are marked in red, and the mean \pm standard deviation is indicated in blue.

Environmental parameters that determine the distribution of Ambrosia artemisiifolia in the grasslands of the Central Caucasus, there was only two climatic indicators - BIO16 (precipitation of the most humid quarter) and BIO13 (precipitation of the most humid month) (Table 5).

Table 5. Contribution of bioclimatic, topographic, and anthropogenic parameters to the formation of the distribution area of the alien species in grasslands

\begin{tabular}{|c|c|c|c|}
\hline Parameter & PC & PI & AUC \\
\hline \multicolumn{4}{|c|}{ Erigeron annuиs } \\
\hline BIO16 & 37.9 & 33.5 & \multirow{3}{*}{0.84} \\
\hline NDVI & 18.6 & 6.8 & \\
\hline $\mathrm{BIO} 1$ & 9.5 & 3.8 & \\
\hline \multicolumn{4}{|c|}{ Ambrosia artemisiifolia } \\
\hline BIO16 & 36.8 & 15.1 & \multirow{3}{*}{0.91} \\
\hline NDVI & 17.2 & 7.5 & \\
\hline BIO13 & 8.9 & 8.2 & \\
\hline \multicolumn{4}{|c|}{ Xanthium albinum } \\
\hline BIO14 & 37.3 & 0 & \multirow{3}{*}{0.85} \\
\hline NDVI & 13.3 & 4.4 & \\
\hline BIO17 & 12.3 & 15.2 & \\
\hline
\end{tabular}

AUC: area under the curve; PC (percentage contribution) contribution to construction of models (\%); PI (permutation importance) - permutation coefficient (\%); BIO13 and BIO16 is precipitation of the most humid month and most humid quarter; BIO14 and BIO17 is precipitation of the driest month and driest quarter $(\mathrm{mm})$; BIO1 is average annual temperature $\left({ }^{\circ} \mathrm{C}\right)$; NDVI is the normalized differential vegetative index in the summer.
The main conditions for invasion and distribution of the species were a fairly narrow range of the precipitation of the most humid quarter and precipitation of the most humid month. The values of this factors were 225-275 $\mathrm{mm}$ and 85-100 mm, respectively (Figure 2). The values of NDVI suitable for invasion of Ambrosia artemisiifolia varied within $0.25-0.38$. More productive plant communities are not suitable for invasion of the species. Thus, the spread of Ambrosia artemisiifolia at present occurs mainly in medium-productive grasslands of foothill and some plain regions with a climate slightly more dry than suitable for Erigeron annuus.

The main climatic parameters for Xanthium albinum distribution in the grasslands, according to Maxent models, there were two indicators - BIO14 and BIO17 (precipitation of the driest month and driest quarter) (Table 5). Acceptable for invasion of the species, the range of precipitation of the driest month was $27-90 \mathrm{~mm}$, and precipitation of the driest quarter on average should not exceed $90 \mathrm{~mm}$ (Figure 2). The values of NDVI suitable for invasion of the species varied within 0.15 0.46 . Thus, factors that limit the distribution of Xanthium albinum in the grasslands of the Central Caucasus are precipitation and productivity of grasslands. This species can spread mainly in dry unproductive (disturbed) grasslands from plains to midmountain regions. 


\section{Discussion}

The purpose of this study was to identify the main vegetation parameters and abiotic factors affecting the distribution of alien species in grasslands of the Central Caucasus. Our results supported previous reports that despite the fact that Ambrosia artemisiifolia, Erigeron annuus, and Xanthium albinum most common in ruderal sites, this species can colonize the meadow ecosystems [16-19].

Multiple regression analysis showed significant increase $(\mathrm{P}<0.05)$ in coverage of Ambrosia artemisiifolia in grasslands with increasing altitude from plains to low mountain regions. The species has a greater distribution in medium-productive disturbed grasslands of foothills and low mountain regions whith relativly low vegetation coverage. These results are in line with previous studies, which observed that a strong competition for habitat resources might inhibit Ambrosia artemisiifolia growth and distribution, and the degree of habitat disturbance affects the abundance of the species $[16,20-22]$. The authors recommended phytocenotic control of Ambrosia artemisiifolia distribution by inducing dominance of perennial native species [20-22]. The most suitable for the species invasion grasslands in the Central Caucasus have moderate humidification (225-275 $\mathrm{mm}$ during the summer). There is controversy over what precipitation regime is more suitable for the species growth and distribution. According to Essl et al. [23], in temperate European climates, Ambrosia artemisiifolia prefers dry soils. On the other hand, Mang et al. [24] reported that in central Europe, the suitability for the species increased with increasing precipitation (to $557 \mathrm{~mm}$ from April to October), which in line whith our results.

We revealed the significant effect of altitude, precipitation, and temperature on the distribution of Erigeron annuus in grasslands. The species can form up to $80 \%$ of vegetation coverage in productive grasslands of foothill and low mountain regions (450-950 m above sea level) with a moderately warm humid climate. Trtikova et al. [25] also reported that from $400 \mathrm{~m}$ above sea level to the altitudinal limit of Erigeron annuus in Switzerland $(1000 \mathrm{~m})$, the plants survived and grew vigorously during the growing season. The authors observed that the climate warming might promote the upward range expansion of the species by reducing winter mortality of seedlings and increasing reproductive productivity in mountain regions [25]. Limited distribution of Erigeron annuus in the plain regions can be probably explained by more pronounced continental climate of plains in the study area, where high value of average annual temperature (over $10^{\circ} \mathrm{C}$ ) is observed.

The level of competition from native species, which is characterized by vegetation coverage, didn't affect the species coverage in the studied grasslands. The species intensively spread within undisturbed grasslands and its distribution accompanied by a decrease in diversity and an increase in degree of dominance of plant communities. Kudryavtseva et al. [26] noted that the seeds of Erigeron annuus inhibited the development of seedlings in a number of native grass species. Cai et al. [27] also demonstrated the high individual-based competitive ability of Erigeron annuus. Liu et al. [28] concluded that the invasion of Erigeron annuus is harmful to species diversity of grass ecosystems in region of Wuling mountain. The importance value of the species in vegetation coverage and the species richness of model plots showed the significant negative relationship [28]. Similar results were obtained by Wang et al. [29] for plant communities of East China. However, according to Trtikova [30], the species was more able to tolerate competition at low altitudes, but this factor hinder the reproduction and distribution of Erigeron annuus at high altitudes, which corresponds to our results.

Analysis of Xanthium albinum range within the grasslands of the Central Caucasus showed that the dry unproductive disturbed pastures of plains and foothills (250-400 $\mathrm{m}$ above sea level) represent the main region of current distribution of the species. Nagornaya [31] also demonstrated that the degree of disturbance of grass ecosystems was one of the most important factors in the distribution of this species in Kursk.

\section{Conclusions}

Our study showed that Ambrosia artemisiifolia, Erigeron annuus, and Xanthium albinum can colonize the grassland ecosystems of the Central Caucasus. The range of Ambrosia artemisiifolia and Erigeron annuus in the grasslands of study area mainly encompassed the foothill and lowland regions, while the most common distribution regions of Xanthium albinum are the plains and foothills.

The main factors affecting the invasion and distribution of Erigeron annuus in grasslands of the Central Caucasus are altitude, precipitation of the most humid quarter, normalized differential vegetation index in summer, and average annual temperature. The most suitable for the species at present are mainly productive grasslands of the foothills and low mountains with a moderately warm humid climate. This competitive species can form up to $80 \%$ of vegetation coverage, and its distribution accompanied by an increase in degree of dominance and a decrease in diversity of plant communities.

The main factors affecting the invasion and distribution of Ambrosia artemisiifolia in grasslands are also altitude, precipitation (in the most humid quarter and month), and normalized differential vegetation index in summer. Important factor is also vegetation coverage that characterizes the level of competition from native species. The most suitable for the species at present are medium-productive grasslands of foothills and low mountains with relatively low vegetation coverage (65$85 \%$ ) and moderately humid climate slightly more dry than suitable for Erigeron annuus.

The main factors affecting the invasion and distribution of Xanthium albinum in grasslands are precipitation of the driest month and driest quarter, normalized differential vegetation index in summer, and 
altitude. Affecting factors are also vegetation parameters characterizing the level of grassland degradation: vegetation coverage, species richness, grass height, Berger-Parker and Shannon indices. The most suitable for the species at present are dry unproductive disturbed grasslands of plains with relatively low vegetation coverage and grass height, species richness and species diversity, and high degree of dominance of grazingresistant secondary pasture dominants.

Thus, while the distribution of Ambrosia artemisiifolia and Xanthium albinum depends largely on anthropogenic disturbance of grasslands, the distribution of Erigeron annuus is limited mainly by climatic conditions - temperature and precipitation. The climate warming might contribute to the expansion of Erigeron annuus in the midmountains and high mountains of the Central Caucasus with the transformation of large areas of steppe and subalpine meadows.

The studies were carried out as part of state assignment no. 075-00347-19-00 on the topic "Patterns of the Spatiotemporal Dynamics of Meadow and Forest Ecosystems in Mountainous Areas (Russian Western and Central Caucasus)."

\section{References}

1. H.B. Wang, J. Sun, Y.X. Yu, Pratac Sci. 127, 68-73 (2007)

2. E. Ruckman, T. Robinson, K. Lyons, S. Schwinning, Ecological Rest. 30, 136-143 (2012)

3. A. Eminniyaz, J. Qiu, C. Baskin, J. Baskin, D.-Y. Tan, Biological Invasions and Its Management in China. (Invading Nature, Springer, 2017)

4. I. Axmanova, V. Kalusova, J. Danihelka, J. Dengler, J. Pergl, P. Pyšek, M. Večeřa, F. Attorre, I. Biurrun, S. Boch, T. Conradi, R. Gavilán, B. Jiménez-Alfaro, I. Knollova, A. Kuzemko, J. Lenoir, A. Leostrin, J. Medvecká, J. Moeslund, M. Chytry, J. Veg. Sci. 32, e12994 (2021)

5. D. Frey, M. Baltisberger, P.J. Edwards, Bot. Helv. 113(1), 1-14 (2003)

6. A.A. Grossheim, Flora of the Caucasus (Baku, 1934)

7. A.W. Sheppard, R.H. Shaw, R. Sforza, Weed. Res. 46, 92-117 (2006)

8. Vasiliev D.S. Recommendations for combating ragweed ragweed (Krasnodar, Knizhnoye izdatelstvo, 1970)

9. A.K.Tembotov, E.A.Shebzukhova, F.A.Tembotova, A.A.Tembotov, I.L. Vorokova, Problems of ecology of mountain areas (Maykop, 2001)

10. TPL (The Plant List), Available at http://www.theplantlist.org (accessed May 2021)

11. R.A. Baldwin, Entropy. 11(4), 854-866 (2009)

12. J. Elith, J.R. Leathwick, Annu. Rev. Ecol., Evol. Syst. 40, 677-697 (2009)

13. R.J. Hijmans, S.E. Cameron, J.L. Parra, P.G. Jones, A. Jarvis, Int. J. Climatol. 25, 1965-1978 (2005)
14. I.D. Moore, R.B. Grayson, A.R. Ladson, Hydrol. Process 5(1), 3-30 (1991)

15. A. Buckley, Understanding curvature rasters, 2010. Available at http:// blogs.esri.com/esri/arcgis/2010/10/27/understandingcurvature-rasters (accessed May 2021)

16. V. Maryushkina, Agr Ecosyst Environ. 36, 207-216 (1991)

17. J.-E. Park, T.-S. Park, S.-B. Song, I.-B. Im, J.-B. Hwang, I.-Y. Lee, Ch.-S. Kim, S.-M. O, J.-R. Jo, J.G. Gang, S. Kim, B.-Ch. Mun, O-S. Gwon, G.-H. Kim, J.-H. Park, N.-I. Park, S.-H. Ji, D.-S. Gang, G.I. Jeong, Korean Journal of Weed Science. 26(1), (2006)

18. I.-Y. Lee, Ch.-S. Kim, J. Lee, K.-J. Hwang, I.-J. Kim, D.-M. Kim, H.-A. Seo, H.-M. Jang, WTS 5, 126-135 (2016)

19. Mirha D., N. Muhamedbegović, D. Gadžo, N. Karic, F. Bašić, N. Sarajlić, Agric. Ecosyst. Environ. 36(34), 207-216 (2017)

20. R. Gentili, F. Gilardelli, S. Ciappetta, A. Ghiani, S. Citterio, Weed Res. 55 (3), (2015)

21. L.A. Arepieva, Contemp. Probl. Ecol. 12, 621-628 (2019)

22. V. Vladimirov, M. Valkova, S. Maneva, M. Senka, Bulg. J. Agric. Sci. 23, 274-279 (2017)

23. F. Essl, K. Biró, D. Brandes, O. Broennimann, J. Bullock, D. Chapman, B. Chauvel, S. Dullinger, B. Fumanal, A. Guisan, G. Karrer, G. Kazinczi, Ch. Kueffer, B. Laitung, C. Lavoie, M. Leitner, Th. Mang, D. Moser, H. Müller-Schärer, S. Follak, J. Ecol. 103, 1069-1098 (2015)

24. Th. Mang, F. Essl, D. Moser, S. Dullinger, Preslia 90. 59-81 (2018)

25. M. Trtikova, P. Edwards, S. Güsewell, Ecography 33, 556-564 (2010)

26. E.I. Kudryavtseva, Y.K. Vinogradova, K.B. Viting, A.M. Kozyreva, A.D. Nefedova, E.G. Petrash, A.S. Stukalov, A.D. Sheynova, N.M. Reshetnikova, Russ J Biol Invasions 11, 225-237 (2020)

27. A.-M. Cai, Y.-G. Song, A. Shabbir, X. He, E.-R. Yan, H. Yan, L. Xu, W. He, Zh.-W. Zhang, Y.-J. Wang, JAPS 27, 1629-1636 (2017)

28. T. Liu, H. Zhang, X. Wang, L. Wu, Acta Sci. Nat. Univ. Sunyatseni 46, 365-370 (2010)

29. C. Wang, M. Wei, Sh. Wang, B. Wu, H. Cheng, Sci. Total Environ. 716, 137128 (2020)

30. M. Trtikova, Bot. Helv. 119, 1-6 (2009)

31. O. Nagornaya, Samara Journal of Science. 7, 78-82 (2018)

\section{Application}

GPS coordinates of Erigeron annuus used in the analysis (according to field research data): 43.477668, 44.154778; 43.458352, 44.163700; 43.575388, 
$44.413129 ; \quad 43.807133, \quad 43.810475 ; \quad 43.336190$, $43.907170 ; \quad 43.294809, \quad 43.864245 ; \quad 43.328526$, $43.887203 ; \quad 43.316939, \quad 44.032201 ; \quad 43.758808$, $43.339620 ; \quad 43.683049, \quad 43.466338 ; \quad 43.637274$, $43.352176 ; \quad 43.610088, \quad 43.103818 ; \quad 43.785567$, $43.168503 ; \quad 43.771134, \quad 42.994088 ; \quad 43.735326$, $42.978408 ; \quad 43.814664, \quad 43.120454 ; \quad 43.698436$, $43.265595 ; \quad 43.650101, \quad 43.419917 ; \quad 43.748275$, $43.172151 ; \quad 43.724076, \quad 43.134684 ; \quad 43.711080$, $43.053675 ; \quad 43.709819, \quad 43.075183 ; \quad 43.736746$, $43.008156 ; \quad 43.107912, \quad 43.553076 ; \quad 43.287414$, $42.706513 ; \quad 43.560118, \quad 43.539627 ; \quad 43.224484$, $43.572732 ; \quad 43.594188, \quad 43.333326 ; \quad 43.489198$, $43.531592 ; \quad 43.698803, \quad 43.265790 ; \quad 43.348520$, 43.669849, etc.

GPS coordinates of Ambrosia artemisiifolia used in the analysis (according to field research data): $43.477542, \quad 44.155491 ; \quad 43.392015, \quad 44.184966$; $43.416925, \quad 44.175426 ; \quad 43.457048, \quad 44.163882$; $43.475733, \quad 44.251714 ; \quad 43.474512, \quad 44.372945 ;$ $43.316939, \quad 44.032201 ; \quad 43.328526, \quad 43.887203$; 43.769077, 43.364924; 43.760056, 43.369693; $43.768085, \quad 43.281042 ; \quad 43.788207, \quad 42.965991 ;$ 43.698436, 43.265595; 43.650101, 43.419917; $43.748275, \quad 43.172151 ; \quad 43.724076, \quad 43.134684$; 43.736746, $\quad 43.008156 ; \quad 43.436540, \quad 43.937782$; $43.496233, \quad 44.151415 ; \quad 43.531944, \quad 44.203387$; 43.494816, 43.778786; 43.532217, 43.757427; 43.560118, 43.539627; 43.882277, 43.046750, etc.

GPS coordinates of Xanthium albinum used in the analysis (according to field research data): 43.748275 , $43.172151 ; \quad 43.724076, \quad 43.134684 ; \quad 43.532217$, $43.757427 ; \quad 43.575388, \quad 44.413129 ; \quad 43.758808$, $43.339620 ; \quad 43.475733, \quad 44.251714 ; \quad 43.496233$, $44.151415 ; \quad 43.494816, \quad 43.778786 ; \quad 43.768085$, $43.281042 ; \quad 43.807133, \quad 43.810475 ; \quad 43.392015$, $44.184966 ; \quad 43.474512, \quad 44.372945 ; \quad 43.316939$, $44.032201 ; \quad 43.328526, \quad 43.887203 ; \quad 43.560118$, 43.539627; 43.882277, 43.046750, etc. 